\title{
AVALIAÇÃO DO USO E OCUPAÇÃO DO SOLO NA REGIÃO NORTE DE CUIABÁ-MT E SUA RELAÇÃO COM A LEI COMPLEMENTAR №102
}

\author{
Andressa Tainara Campelo de Jesus ${ }^{1}$ \\ Mariza de Mello Arruda Sampaio ${ }^{2}$ \\ Allyf Kumakura Alves ${ }^{3}$ \\ Kaira Cristina de Macedo ${ }^{4}$
}

\begin{abstract}
RESUMO
O rápido e desordenado processo de urbanização, aliados aos modelos de ocupação do solo, comprometeram a qualidade ambiental das grandes cidades, resultando em significativas alterações no clima urbano e, em relação ao conforto ambiental e à saúde física e psicológica da população. As alterações experimentadas pela urbanização modificam o clima urbano pelas alterações no relevo, pelas variações na rugosidade do solo e pela diminuição da cobertura vegetal, além de muitos outros fatores. Esta pesquisa trata da relação entre as modificações nas variáveis microclimáticas e a Lei Complementar de uso e ocupação do solo $n^{\circ} 102$, na região Norte da cidade de Cuiabá-MT. Para isso, analisou-se três pontos na Avenida Historiador Rubens de Mendonça, um dos principais eixos de expansão da cidade, em um período de 10 anos entre 2003/2004 e 2013/2014. Comparouse dados de temperatura e umidade relativa de ar com as mudanças sofridas pelas áreas analisadas, através de parâmetros legais como os recuos das edificações, presença de vegetação e a permeabilidade. Os resultados da pesquisa permitiram afirmar que as condições climáticas estão diretamente ligadas ao uso do solo e, principalmente com a carência de indivíduos arbóreos no local. Como conclusão, revelou-se a necessidade de adequação do espaço territorial às diretrizes legais do planejamento urbano.
\end{abstract}

Palavras-chave: Conforto térmico. Legislação. Planejamento urbano.

Recebido em: 29/03/2016 | Aceito em: 02/08/2016

\footnotetext{
${ }^{1}$ Estudante de Engenharia Civil, Aluna no programa de Iniciação Científica na Universidade Federal de Mato Grosso, na área de Conforto Ambiental. E-mail: andressatainara_@hotmail.com

${ }^{2}$ Professora da UFMT, atuando na área de Projeto e Representação Gráfica, possui graduação em Arquitetura e Urbanismo pela Universidade Federal de Mato Grosso (2003), mestrado em Física Ambiental pela Universidade Federal de Mato Grosso (2006) e doutorado em Urbanismo pelo PROUrb/ Universidade Federal do Rioo de Janeiro (2015). E-mail: marizasampaio@outlook.com

${ }^{3}$ Estudante de Engenharia Civil, Aluno no programa de Iniciação Científica na Universidade Federal de Mato Grosso, na área de Conforto Ambiental. E-mail: makurallyf@hotmail.com

${ }^{4}$ Estudante de Engenharia Civil, Aluna no programa de Iniciação Científica na Universidade Federal de Mato Grosso, na área de Conforto Ambiental. E-mail: kairamacedo@outlook.com
} 


\section{INTRODUÇÃO}

Kotkin (2012) afirma que a maior criação da humanidade foi suas cidades. Elas representam a extrema realização de nossa imaginação enquanto espécie, atestando nossa capacidade de reformar o ambiente natural das maneiras mais profundas e duradouras.

SIMON (2006) descreve a paisagem urbana como o meio espacial no qual acontecem as atividades e é consequência do modo como a comunidade conduz o processo construtivo de seu meio de realizações. Assim, as alterações processadas nos interesses da sociedade provocam alterações na configuração da cidade.

As áreas urbanas concentram atualmente grande parte da população mundial e das atividades econômicas, sociais, culturais, o que resulta numa demanda e consumo crescentes de energia, água e outras matérias primas. (MACIEL, 2011). Porém seu crescimento no espaço, ao longo do século $X X$, se apresentou de maneira intensa e desigual. (FIALHO, 2012).

A urbanização acelerada tem comprometido a qualidade ambiental das grandes cidades, sobretudo pela perda da cobertura arbórea e a má ocupação dos solos que interferem diretamente na rugosidade do terreno, diminuindo a ventilação natural (SILVA; GONZALES; FILHO, 2011). Segundo MONTEIRO (1976), a soma desses fatores trouxe à população manifestações ligadas aos impactos pluviais, ao conforto térmico e a formação de ilhas de calor.

Para Bernatzky (1982), a formação das ilhas de calor ocorre devido às massas de edificações, aos materiais das construções e vias públicas que absorvem grande quantidade de radiação solar, à redução da velocidade do vento pelos prédios, à poluição que reduz a perda de radiação de onda longa, pelas superfícies para o céu, 5causando aquecimento atmosférico, à drenagem insuficiente pelo sistema de captação de águas pluviais, à não filtração de água no solo como consequência da utilização de revestimentos impermeáveis e a redução da energia utilizada nos processos de evapotranspiração realizados pela vegetação.

A vegetação desempenha diversas e importantes funções como elemento do espaço urbano: ornamentais; paisagísticas; controle de ruídos e filtragem da poluição atmosférica e ainda, atuando como elemento modificador do microclima, adequando o comportamento térmico do arranjo urbano. "A contaminação do ar 
pode ser reduzida com um cinturão verde, efeito que pode ser conseguido com árvores plantadas ao longo de uma avenida", (ROMERO, 2001). No estudo realizado por Hoffman e Shashua-Bar (2000), em Tel-Aviv, constatou-se que o efeito amenizador climático de pequenas áreas verdes pode ser sentido até um raio de cem metros distante das mesmas. Além disso, a presença da vegetação tem implicações termodinâmicas que repercutem decisivamente no desempenho energético da cidade.

A vegetação arbórea que proporciona sombra ajuda a manter a temperatura do ar interno nas edificações, diminuindo o seu aquecimento, além de resfriar a temperatura externa. Além de mitigar as ilhas de calor, a presença de vegetação também contribui para o escoamento superficial, diminuindo as enchentes, porque capturam a água da chuva em suas folhas, galhos e troncos e reduzem e retardam a quantidade de água que atinge o sol (AMORIM, 2010).

Carvalho (2001) constatou a relevância das áreas verdes no clima das cidades, ainda segundo a autora em seu estudo foi observado benefícios relevantes no processo de amenização climática no meio urbano, pela criação de microclimas agradáveis, que contribuíram de forma significativa, para o conforto térmico dos núcleos urbanos.

Sob o ponto de vista ambiental, o conforto é definido como o estado mental que expressa à satisfação do homem com o meio ambiente térmico que o circunda (LAMBERTS et al., 2011). Para LIMA \& NERY (2008), a sensação de conforto depende do nível de importância da temperatura, da umidade e da ventilação, que não pode ser desvinculada dos demais elementos climatológicos: a temperatura alterada de uma cidade leva a variação na ventilação da cidade, que interfere na condensação e precipitação.

No Brasil, o processo de urbanização se tornou mais acelerado a partir da década de 1960, a partir de um intenso êxodo rural. O crescimento das cidades ocorreu sem a implantação de infraestrutura urbana adequada ou suficiente para que não ocorresse a degradação do ambiente. (AMORIM, 2010). Os planos diretores que surgiam nesses momentos fizeram surgir um padrão de crescimento urbano baseado na expansão extensiva das áreas periféricas e um crescimento intensivo nas áreas centrais, resultando em adensamento e verticalização. 
Segundo Gomes (2009), obteve-se um distanciamento entre o projeto de cidade proposto nos planos e a cidade real configurada na prática, o que atestou para a incapacidade do planejamento em resolver os problemas urbanos. Diante dessa realidade urbana foi aprovado em 2001 o Estatuto da Cidade (Lei Federal 10.257), que criou instrumentos urbanísticos que subordinam a propriedade urbana (direito de propriedade) ao cumprimento de sua função social (direito coletivo).

Segundo Alves da Silva (2013), o Estatuto da Cidade aparelhou a administração pública através de instrumentos técnicos de gestão do espaço urbano. O Plano Diretor é o que define as diretrizes urbanísticas, as normas de adensamento e de expansão territorial além de definir as zonas de uso e ocupação de solo e a localização das redes de infraestrutura. Para a definição do Uso e Ocupação do Solo, a legislação traz o zoneamento da cidade, que deve conter as especificidades de cada região da cidade.

Nos últimos vinte anos, a cidade de Cuiabá sofreu uma rápida e desordenada expansão urbana, o que aliado a um planejamento ineficaz do poder público, resultou em modificações ambientais. A construção de edifícios modificou o fluxo natural dos ventos. A superfície do solo foi quase totalmente revestida por materiais impermeáveis e é visível a diminuição de vegetação nas vias públicas e quintais nas regiões mais adensadas e antigas de Cuiabá (SAMPAIO, 2015). Com isso, acentuou-se o rigor climático de uma cidade que possui como principal característica as altas temperaturas anuais

Maitelli (1994) foi quem primeiro apresentou um trabalho lidando com aperspectiva do balanço de energia em área urbana em Cuiabá/MT, investigando osefeitos da urbanização na temperatura e umidade do ar na cidade, sendo este um dospoucos estudos em área continental do país. As medidas do balanço de energia nocentro urbano mostraram altas taxas de calor armazenado, sendo que oscomportamentos das variáveis do balanço puderam explicar aspectos da ilha de calore do regime de umidade na cidade. Duarte (2002) verificou o grau de correlaçãoentre variáveis mais ligadas à legislação urbana, tais como a taxa de ocupação, ocoeficiente de aproveitamento, a presença de água e de vegetação, com a temperaturado ar na cidade de Cuiabá, MT.

Santos (2012) analisou a influência da ocupação do solo no microclima emCuiabá-MT-Brasil por meio das diferenças de temperatura e umidade do ar 
intraurbana do município. Para tanto, foi usada a metodologia de transectos móveis noturnos nas quatros estações do ano, $\mathrm{O}$ adensamento urbano e a supressão de vegetação são fatores determinantes na modificação do comportamento termohigrométrico, sendo evidente a influência do fluxo de veículos automotores nosganhos de calor no meio, enquanto que áreas sob influência de grandes massas devegetação, apresentaram características próprias, com microclimas diferentes dasoutras áreas da cidade. Este estudo contribui para diagnosticar eventuais mudançasno clima urbano devido ao processo de crescimento de Cuiabá, que precisam serconsiderados pelos planejadores e gestores para que sejam tomadas medidas quecontribuam com a melhoria da qualidade ambiental e de vida da população.

Leão (2007) realizou um estudo empregando a carta bioclimática de Cuiabá nas estratégias do condicionamento térmico das edificações. Neste artigo ficou constatado que a falta de ventilação na região é um dos fatores agravantes da falta de conforto. Por isso, os autores recomendam cuidados com as taxas de adensamento e zonas de expansão, como uma forma de evitar que as barreiras físicas sejam criadas na direção dominante do vento.

Tal situação aponta para a necessidade de revisão dos modelos de cidade,da legislação de construção urbana e dosprocessos de planejamento urbano (ASSIS, 2006). Segundo Olgyay (1963), tal projeto deve envolver o clima, o homem e o hábitat, buscando as condições favoráveis do clima, com a intenção de satisfazer as exigências humanas de conforto térmico.

Em Dezembro de 2003 foi sancionada a LEI COMPLEMENTAR N. 102 que regula o uso e ocupação do solo em Cuiabá, Mato Grosso, sendo que os seus principais objetivos consistem em registrar informações técnicas sobre as construções na cidade; assegurar os padrões mínimos de segurança, higiene, salubridade e conforto das edificações de interesse para a comunidade; e controlar e acompanhar a evolução do espaço urbano construído. (SAMPAIO, 2015).

A LEI COMPLEMENTAR N.102 DE 03 DE DEZEMBRO DE 2003 versa que:

"A Ocupação do Solo Urbano, aferida pela quantidade, intensidade e disponibilidade de área a ser construída, fundamenta-se nos seguintes conceitos e parâmetros: 
I - POTENCIAL CONSTRUTIVO - (PC) - é a área total edificável em um lote, definido através do Coeficiente de Aproveitamento e limitada por sua Capacidade Construtiva;

II - COEFICIENTE DE APROVEITAMENTO - (CA) - é a relação entre a área total edificável em um lote e sua área, conforme legislação vigente até a publicação da presente Lei;

III - CAPACIDADE CONSTRUTIVA - (CC) - é a maior área edificável em um lote, em função da infra-estrutura disponível;

$$
\text { IV - LIMITE DE ADENSAMENTO - (LA) - é o coeficiente entre a }
$$
Capacidade Construtiva de um lote e sua área;

$V$ - POTENCIAL CONSTRUTIVO EXCEDENTE - (PCE) - é a parcela do Potencial Construtivo vinculado a um lote que ultrapasse a sua Capacidade Construtiva;

VI - COEFICIENTE DE OCUPAÇÃO - (CO) - é a relação entre a área da projeção da edificação no lote e a área do lote;

VIII - COEFICIENTE DE PERMEABILIDADE - (CP) - é a relação entre a área mínima permeável a ser mantida no lote e a área do próprio lote;

IX - AFASTAMENTO FRONTAL MÍNIMO - (AFM) - é a distância mínima entre a projeção de uma edificação e o eixo geométrico da via lindeira ao lote edificado;

Parágrafo Único. A legislação regulamentadora de que trata o Artigo 73 poderá definir ÁREAS NÃO COMPUTÁVEIS para efeito de cálculo dos parâmetros definidos no CAPUT deste artigo, de acordo com peculiaridades específicas de cada USO ou ZONAS ESPECIAIS.

Parágrafo Único. Para qualquer edificação, a expedição do "Habite-se", estará condicionada ao plantio de uma árvore na calçada, devidamente protegida com grade, a cada 5,00 m (cinco metros) de testada, devendo ainda ser observada a orientação técnica do órgão de Planejamento do Município - IPDU"8.

Para Lima (2011) o planejamento ambiental do território converte-se em um elemento para a elaboração dos programas de desenvolvimento econômico e social, e para a otimização do plano de uso, manejo e gestão de qualquer unidade territorial e deve estar presente no Plano Diretor. O plano diretor deve conduzir as ações para 
o caminho do desenvolvimento sustentável, uma vez que o meio urbano é considerado um sistema dinâmico de atividades humanas.

Nas recentes edições do Encontro Nacional de Conforto no Ambiente Construído (ENCAC) de 2013 e eventos semelhantes (Passive andLow Energy Architecture - PLEA, Passive andLow Energy Cooling for theBuiltEnvironment PALENC) de 2013 e 2014, vêm-se notando a separação de temas voltados, basicamente, a duas vertentes distintas: o conforto em ambientes internos, englobando as áreas de acústica, térmica e iluminação; e o clima urbano, tratando de espaços externos, (KRÜGER; DRACH; EMMANUEL; CORBELLA, 2012). Conforme observa Emmanuel (2005), torna- se necessário expandir o conhecimento, além das considerações climático-determinísticas de edificações isoladas, definindo limites e condições microclimáticas ideais a serem almejadas em espaços externos. A partir de tais condições, o papel do planejamento seria utilizar recursos diversos (estratégias de sombreamento, inserção de praças e áreas de vegetação, adoção de fontes d'água, entre outros), de modo a se alterar de forma benéfica o microclima de espaços urbanos.Desse modo, o conhecimento de parâmetros que qualifiquem e quantifiquem os benefícios trazidos pela vegetação na amenização do comportamento climático nos recintos urbanos é de grande importância para profissionais que atuam no planejamento urbano.

Utilizando-se de tais critérios, procura-seprover o crescimento da cidade de maneira sustentável, objetivando a adequada utilização do solo, a proteção ambiental, o desenvolvimento social e econômico, e a melhoria da qualidade de vida da população, interferindo direta ou indiretamente na ambiência térmica urbana da cidade de Cuiabá.

Sendo assim, o objetivo dessa pesquisa consiste em analisar parâmetros da Lei Complementar $n^{\circ} 102$ de Uso e Ocupação do Solo, no município de Cuiabá-MT, relacionando-os ao comportamento das variáveis microclimáticas em relação ao meio urbano. 


\section{MATERIAIS E MÉTODOS}

\section{1 Área de estudo}

A cidade de Cuiabá, capital do estado de Mato Grosso, situa-se no centro geodésico da América do Sul, entre as coordenadas geográficas de 15³5'56" latitude sul e $56^{\circ} 06^{\prime} 01^{\prime \prime}$ longitude oeste. Pertence à região Centro-Oeste do Brasil e localiza-se na chamada Depressão Cuiabana, Possui área de $3.538,17 \mathrm{~km}^{2}$, correspondendo $254,57 \mathrm{~km}^{2}$ à Macrozona Urbana e $3.283,60 \mathrm{~km}^{2}$ à Área Rural (IPDU, 2007).

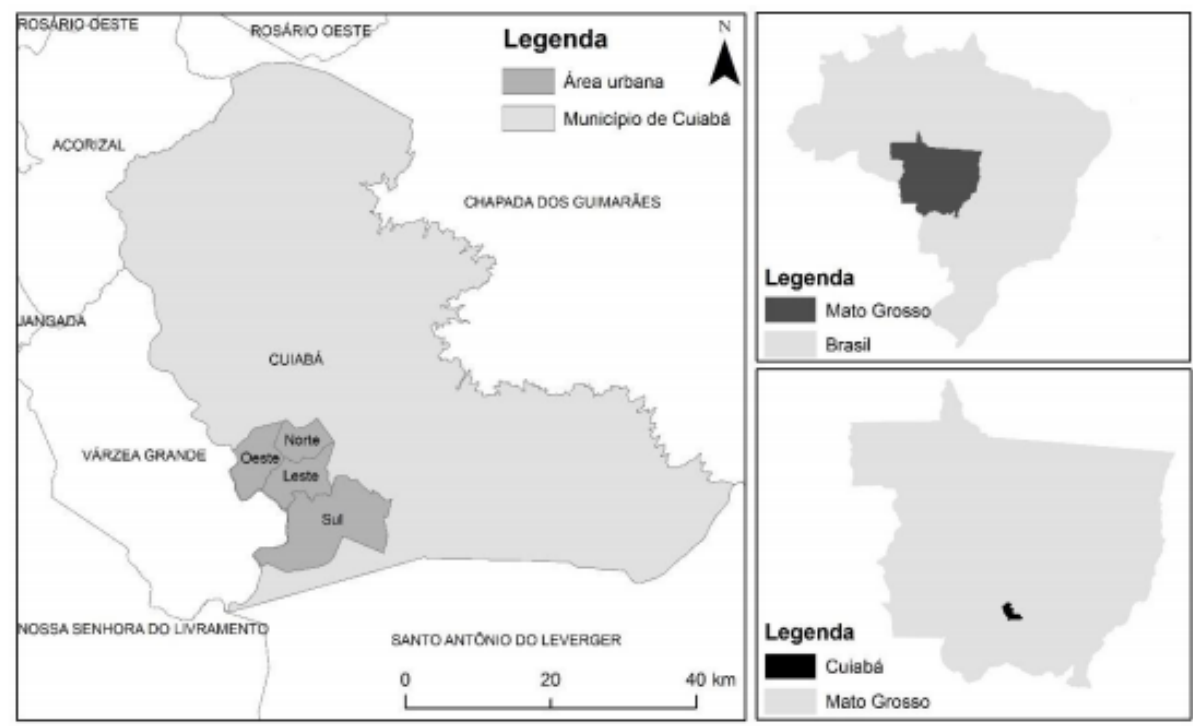

FIGURA 1 -Localização geográfica de Cuiabá/MT

Fonte:http://www.dsr.inpe.br/sbsr2015/files/p0377.pdf

Segundo a classificação do Köppen, o clima é do tipo Aw, ou seja, tropical semi-úmido, sendo constante a presença de temperaturas elevadas com média anual em torno de $26 \stackrel{\circ}{\circ}$, apresentando duas estações bem definidas: uma seca (outono-inverno) e uma chuvosa (primavera-verão).

A Zona Norte de Cuiabá é composta por 67 localidades, distribuídas em dez bairros e duas áreas de expansão urbana. Possui uma área de 3070 hectares e uma população de 113.704 habitantes (IPDU, 2007). O crescimento dessa área está relacionado, sobretudo, à construção do Centro Político Administrativo (CPA), sendo considerada, na atualidade, um dos eixos de centralidade urbana, com a presença 
de diversos edifícios de alto padrão, comércios e a recente implantação de condomínios horizontais fechados.

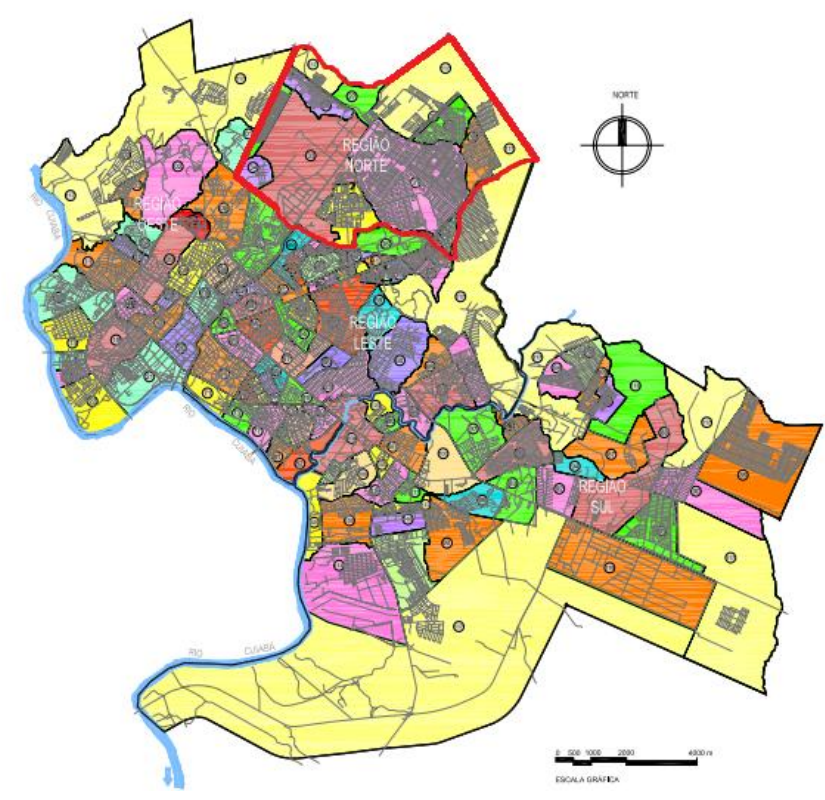

FIGURA 2 -Localização da área de estudo

Fonte: http://www.cuiaba.mt.gov.br/upload/arquivo/composicao_bairros.pdf

\subsection{Materiais e Métodos}

O procedimento adotado como referencial teórico-metodológico foi o de KATZCHNER (1997), que analisa as condições do clima urbano segundo características qualiquantitativas. Seguiu-se um roteiro metodológico,usado por outros autores, como MENDONÇA (1994), que consiste em: definição dos pontos de análise, coleta de imagens, análise qualitativa dessas, levantamento de dados climáticos e análise quantitativa comparativa dos dados.

Para o desenvolvimento da pesquisa foram selecionados três pontos para obtenção dos dados, na zona norte da cidade de Cuiabá. Todos esses pontos se localizam na Avenida Historiador Rubens de Mendonça, conhecida como Avenida do CPA (Centro Político Administrativo), local já definido por outros autores, como uma das mais quentes do município (MAITELLI, 1994).

Os pontos foram assim denominados: 
- Ponto A, localizado na Avenida Historiador Rubens de Mendonça, conhecida como Avenida do CPA (Centro Político Administrativo) próximo ao viaduto da Avenida Miguel Sutil

- Ponto B, situado na Avenida Historiador Rubens de Mendonça, conhecida como Avenida do CPA (Centro Político Administrativo) próximo a um shopping da cidade;

- O ponto C, localizado na Avenida Historiador Rubens de Mendonça, conhecida como Avenida do CPA e dá acesso a noroeste ao Centro Político Administrativo e a nordeste aos bairros CPA I e II.

Os pontos foram locados sob a ótica da Lei Complementar $\mathrm{n}^{\circ} 102$, visando a análise do uso, permeabilidade e ocupação do solo e avaliação do entorno. Assim, obteve-se locais em diferentes configurações, objetivando investigar a ocorrência de diferenças de temperatura na área trabalhada.

Para caracterizar o uso do solo, utilizou-se imagens de satélite, por meio do Google Earth, de cada ponto selecionado, com uma abrangência de 200 metros em seu entorno, em dois períodos, nos anos de 2004 e 2014. Logo, verificou-se parâmetros como o tipo de material utilizado no revestimento do solo, afastamentos mínimos entre edificações e o plantio regular de árvores a cada $5 \mathrm{~m}$ ao longo da edificação.

Após a escolha dos pontos para a análise, realizou-se o levantamento dos dados climatológicos referentes à temperatura média e umidade, nos períodos compreendidos entre os meses de novembro à agosto de 2003-2004 e 2013-2014, extraídos do levantamento realizado pelo Grupo de Pesquisas em Geografia da Universidade Federal do Mato Grosso.

O levantamento de dados climáticos reúne gráficos referentes a informações climatológicas de 2003 e 2004, além de todos os dados de variáveis microclimáticas, tais como as normais climatológicas locais para categorizar o clima regional; tabelas e gráficos referentes às variações mínimas, médias e máximas da temperatura e da umidade relativa do ar, precipitações, radiação solar, pressão atmosférica, evaporação, insolação, nebulosidade; e gráficos da variação anual do vento, velocidades e direção média do vento, além dos dados microclimáticos atuais coletados que vão de novembro de 2013 a setembro de 2014, englobando os períodos de chuva e seca da região, permitindo uma abordagem geral comparativa 
após 10 anos de promulgação da Lei municipal a ser analisada através do cruzamento desses dados.

Escolheu-se o método de medidas de transectos móveis para esta pesquisa e, utilizou-se duas estações fixas, com registradores de temperatura. Além disso, abrangeram as estações de chuva e seca, sendo coletados em condições estáveis de tempo atmosférico (céu aberto e calmaria e ventos fracos), próximas das observadas diariamente em Cuiabá.

Os dados de transecto foram montados num veículo teletermométrico com precisão de $0,1^{\circ} \mathrm{C}$. O transmissor foi protegido e montado $1 \mathrm{~m}$ acima do teto do automóvel que tinha, conforme referência de Lombardo (1985) cor clara para evitar efeitos de radiação. As observações foram feitas com veículo parado e com ventos inferiores a $2 \mathrm{~m} / \mathrm{s}$, sendo a condição de calmaria a ideal. Uma das relações entre o ambiente edificado e a temperatura, que interessa em Climatologia Urbana, e que foi observada durante as medições é a que pode ser estabelecida entre a "fator de visão do céu" ("skyviewfactor") e as variações térmicas.

As medições foram realizadas com velocidade do veículo entre 30 e 40 $\mathrm{km} / \mathrm{h}$, não ultrapassando uma hora no percurso do transecto, nos horários de 8:00h, 14:00h e 20:00h. Os pontos foram escolhidos por diferenças de ocupação do solo ao longo dos transectos. Parou-se com o carro em cada ponto por 1 minuto, obtendo-se 10 dados instantâneos do local, utilizando-se 8 dados, desconsiderando-se os 2 primeiros para estabilização do aparelho. Foram coletados 5 dias de cada mês, de novembro de 2013 à agosto de 2014, sendo 3 medições diárias conforme os horários citados acima.

\section{RESULTADOS E DISCUSSÕES}

A seguir serão apresentadas as análises dos dados coletados e discussões dos parâmetros necessários às investigações da influência dos aspectos legais da Lei Complementar $n^{0} 102$ e a ambiência térmica urbana. 


\subsection{Análise do uso e ocupação do solo}

Comparando-se as imagens de $2004 \mathrm{com}$ as de 2014, para o ponto A, percebe-se poucas alterações no local, sendo mais notáveis as obras para implantação do VLT (Veículo Leve sobre Trilhos), ainda inacabadas. Nota-se a presença essencial de condomínios verticais e edifícios comerciais e a ausência de recuos entre as edificações, tornando a área densa. A vegetação é bastante suprimida e essencialmente arbustiva, predominando revestimentos de asfalto e concreto.
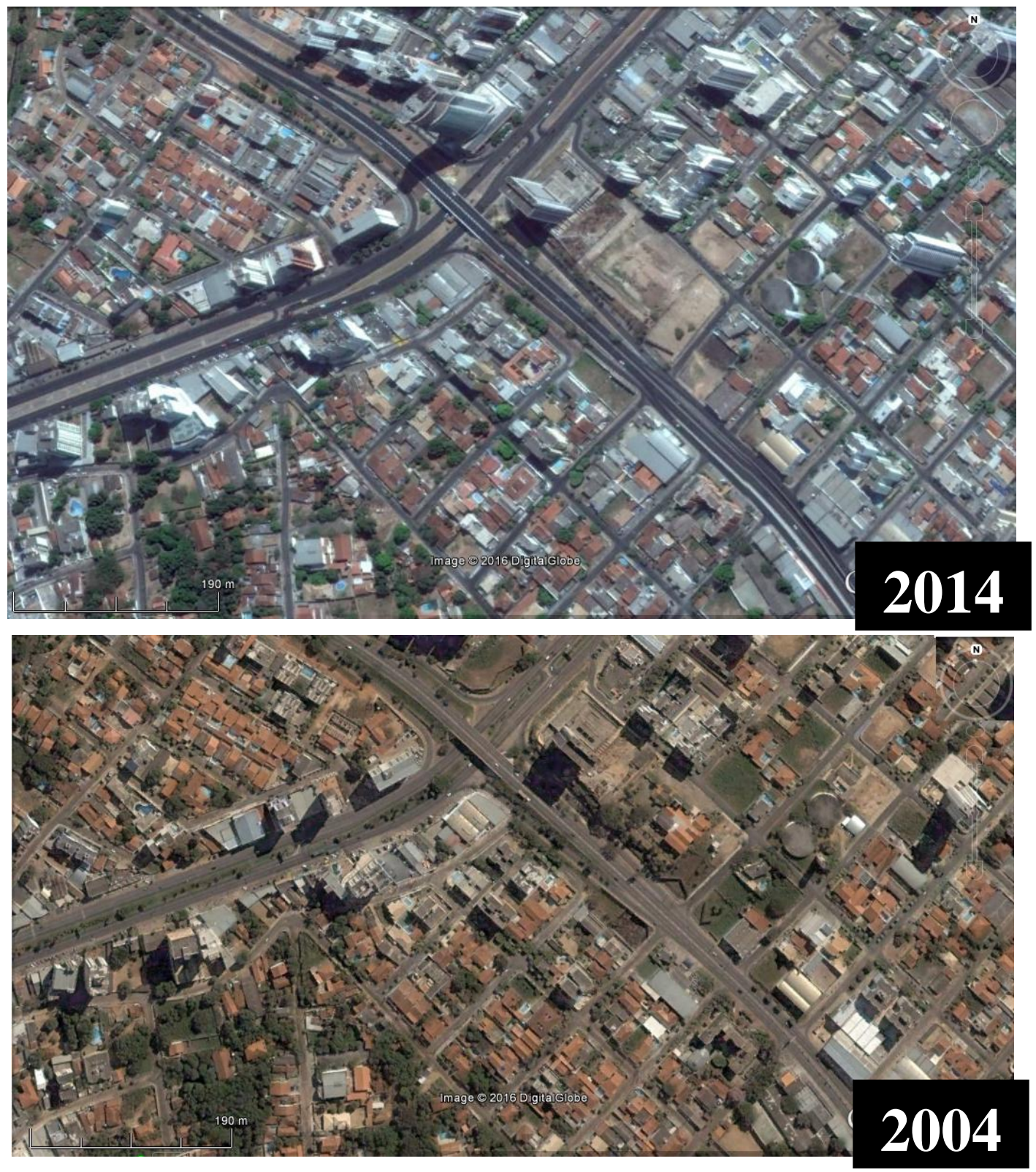

FIGURA 3 - Ponto A - Avenida Historiador Rubens de Mendonça ( $15^{\circ} 35^{\prime} 19.44$ " S, 56 $05^{\circ} 04.26^{\prime \prime}$ O) em 2004 e 2014

Fonte: Google Earth (acesso em 2016)

Ciência e Sustentabilidade - CeS | Juazeiro do Norte v. 2, n. 1, p. 103-123, jan/jun 2016 
O ponto B localiza-se próximo ao maior shopping da cidade, predominando em seu entorno o revestimento asfáltico, com calçadas em concreto. Em 2003/2004, notava-se a presença de grandes terrenos vazios com solo exposto, o que favoreceu a implantação de imóveis. Possuía, também, canteiro central e calçadas arborizadas com gramíneas e árvores de pequeno porte. No entanto, em 2013/2014, com as obras de adequação da cidade para a Copa de 2014, o local passou por grandes alterações, devido principalmente à construção do viaduto Jamil Boutros Nadaf, mais conhecido como "viaduto da Sefaz". Esse elevado, em forma de ferradura, foi inaugurado em 2014 e retirou grande parte da vegetação dos canteiros, o que não condiz com a Lei Complementar $n^{\circ} 102$, que prevê o plantio de uma árvore a cada 5 metros.

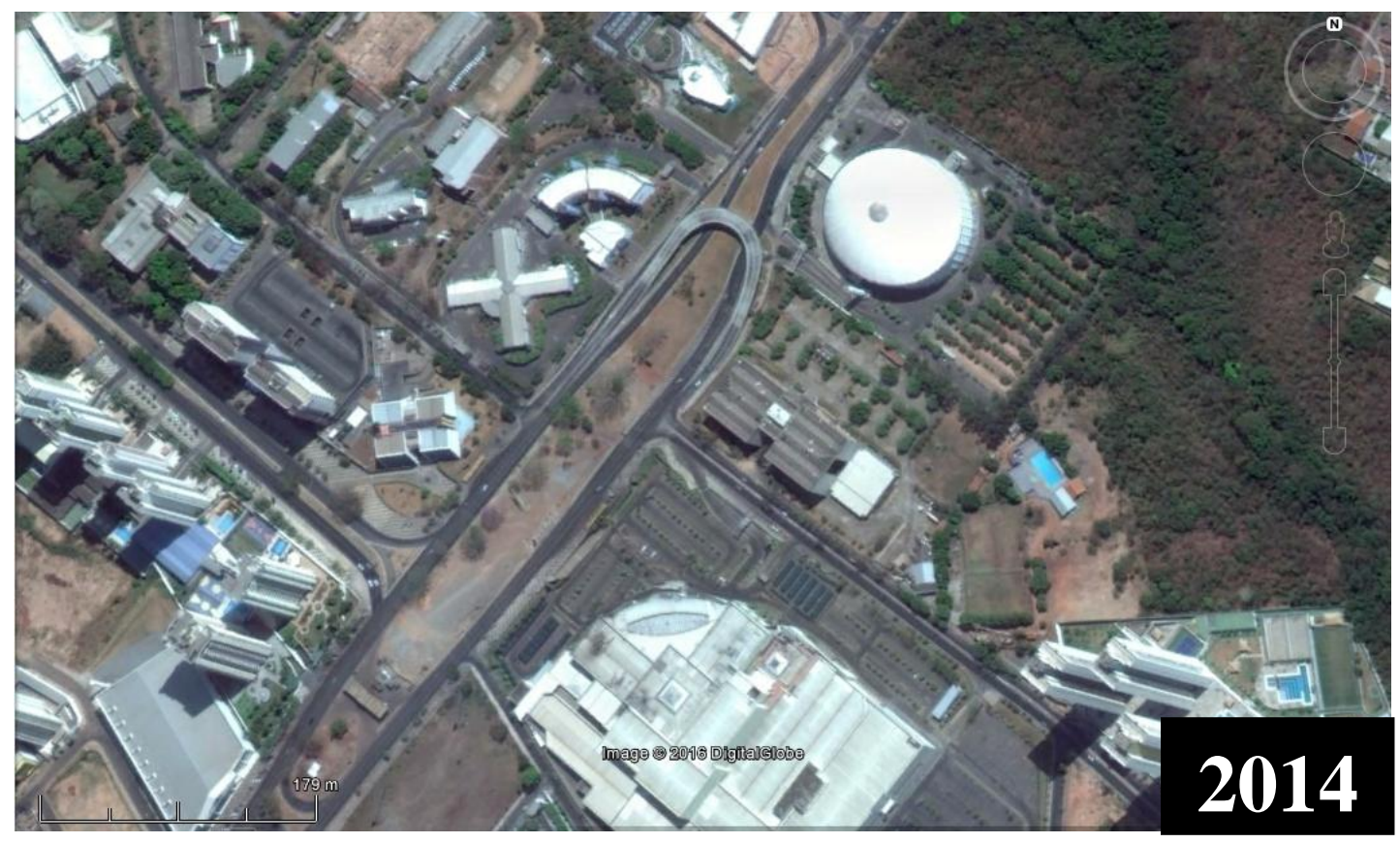




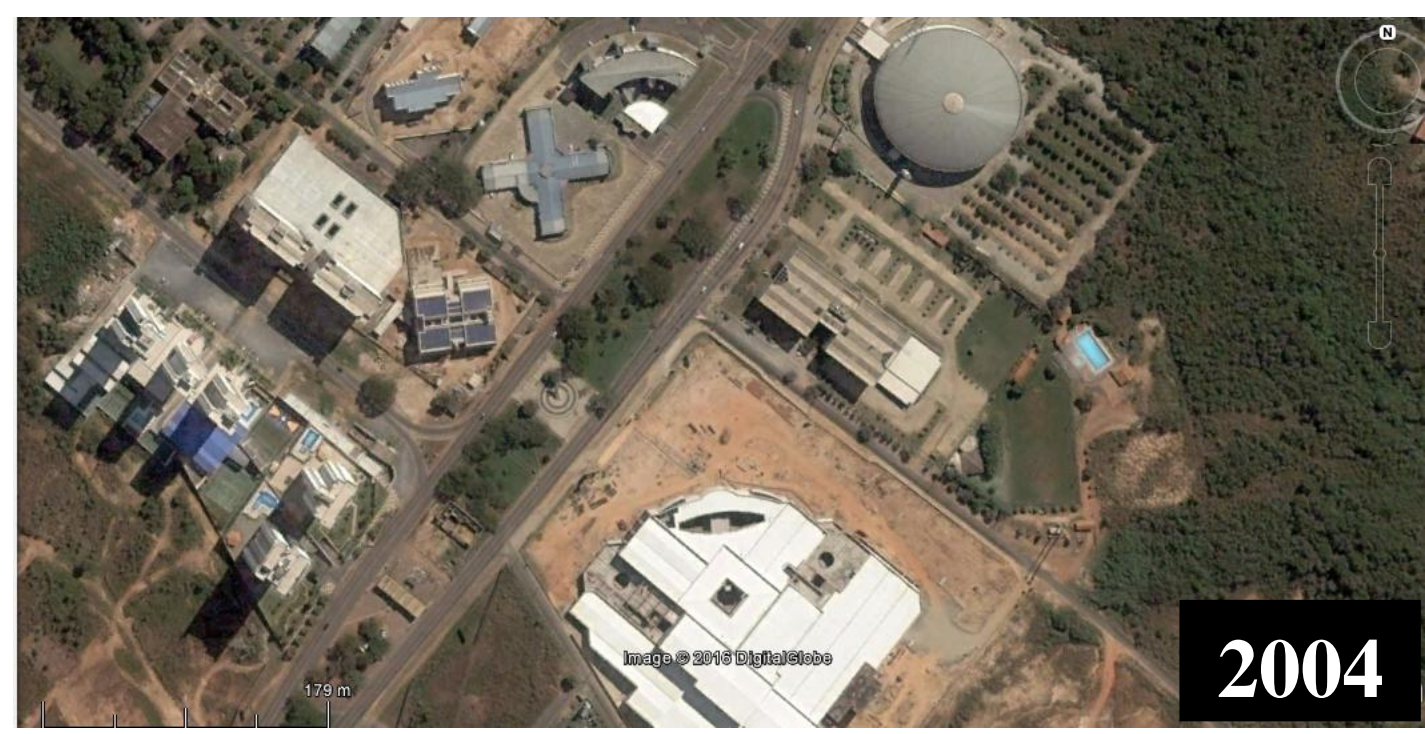

FIGURA 4 - Ponto B - Avenida Historiador Rubens de Mendonça, Mendonça (15 ${ }^{\circ} 34^{\prime} 31.81^{\prime \prime} \mathrm{S}, 56^{\circ}$ 04' 21.26" O), em 2004 e 2014

Fonte: Google Earth (acesso em 2016)

Percebe-se para o ponto $C$ que, grande parte da vegetação da área se manteve praticamente inalterada devido à localização do Parque Massairo Okamura, à sudoeste, que por abrigar a nascente do Córrego do Barbado, caracteriza-se como área de preservação ambiental. Comparando-se as imagens de 2013/2014 com aquelas obtidas em 2003/2004, percebem-se poucas alterações, com exceção da ocupação de alguns terrenos anteriormente vazios. Há predominância de residências unifamiliares, porém não se nota a adequação dos recuos previstos na Lei de Uso e Ocupação do Solo.

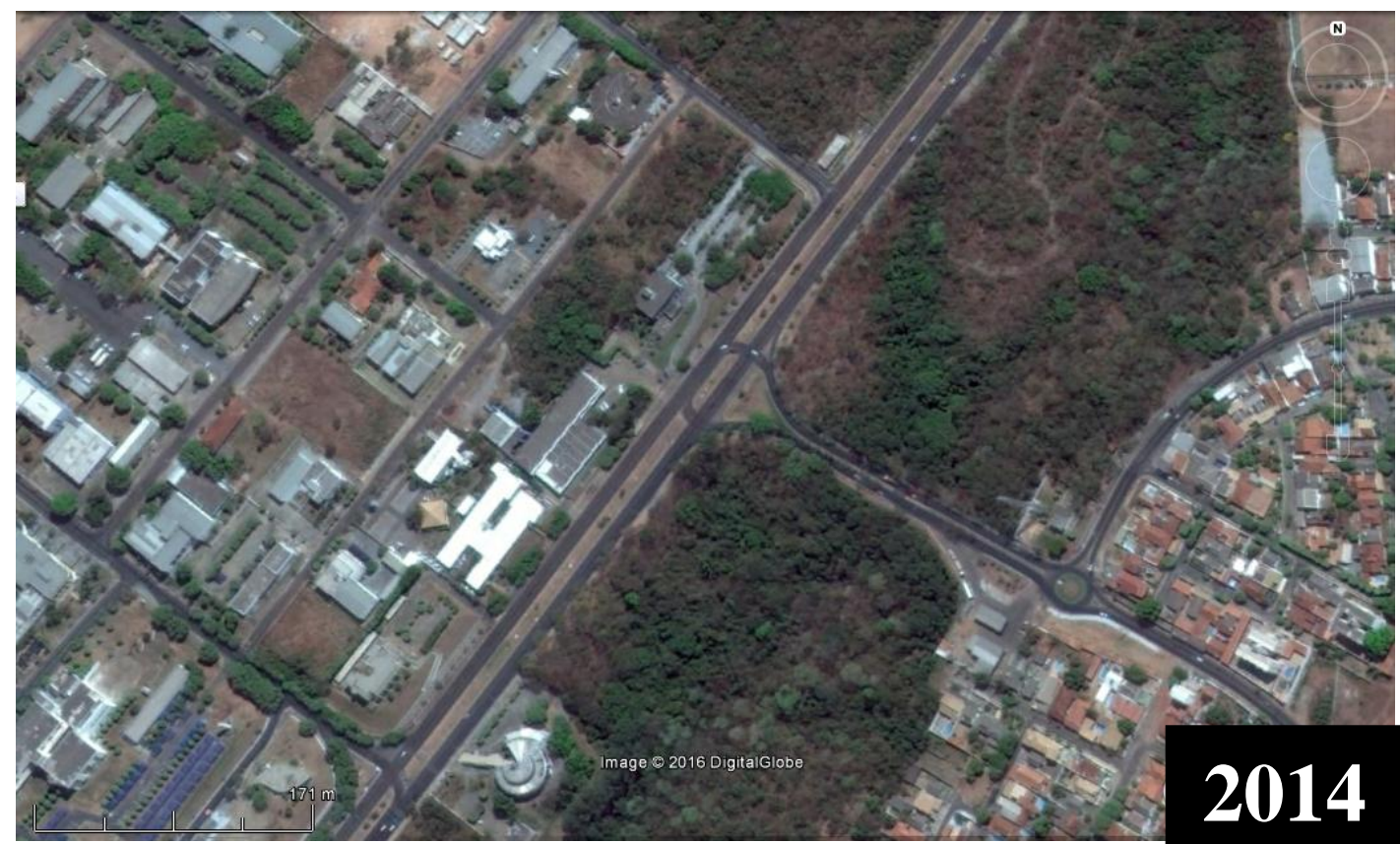

Ciência e Sustentabilidade - CeS | Juazeiro do Norte v. 2, n. 1, p. 103-123, jan/jun 2016 


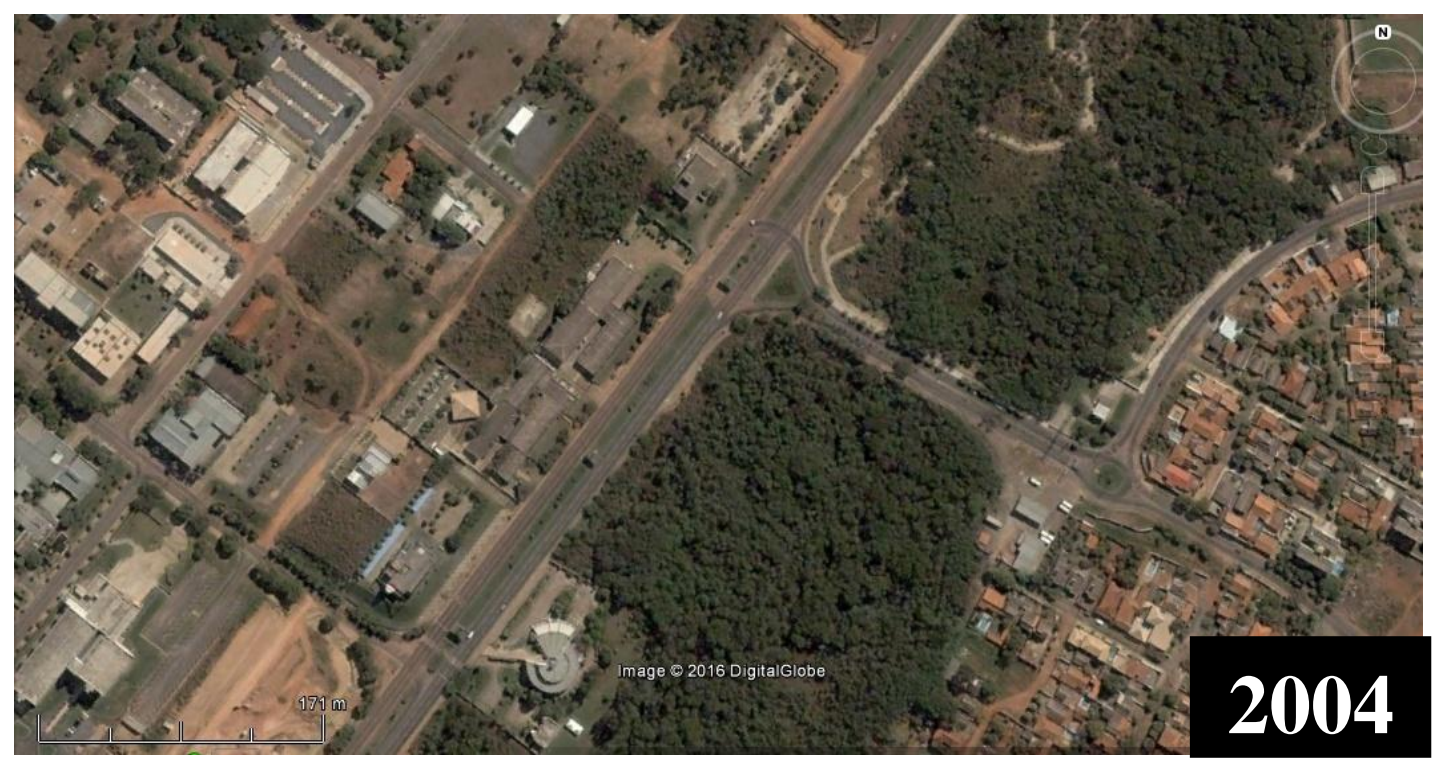

FIGURA 5 - Ponto C - Avenida Historiador Rubens de Mendonça, Mendonça ( $15^{\circ} 34^{\prime} 02.55^{\prime \prime} \mathrm{S}, 56^{\circ}$ 04' 06.67" O), em 2004 e 2014

Fonte: Google Earth (acesso em 2016)

O resultado ambiental de todos os pontos pode ser observado na tabela 1, juntamente com sua relação, positiva se de acordo com a legislação estudada e negativa se em descumprimento desses parâmetros:

\begin{tabular}{|l|c|c|c|c|}
\hline Ponto & Vegetação & Urbanização & $\begin{array}{c}\text { Avaliação } \\
\text { ambiental }\end{array}$ & $\begin{array}{c}\text { Conformidade com a } \\
\text { Lei N } \mathbf{N}^{\mathbf{1 0 2}}\end{array}$ \\
\hline Ponto A & Diminuiu & Aumentou & Negativo & $\begin{array}{c}\text { Não atendeu as } \\
\text { exigências }\end{array}$ \\
\hline Ponto B & Diminuiu & Aumentou & Negativo & $\begin{array}{c}\text { Não atendeu as } \\
\text { exigências }\end{array}$ \\
\hline Ponto C & Aumentou & Aumentou & Positivo & \begin{tabular}{c} 
Seguiu parcialmente a lei \\
\hline
\end{tabular} \\
\hline \multicolumn{3}{|c|}{ TABELA 1-Quadro comparativo do resultado ambiental de todos os pontos } \\
\hline
\end{tabular}

\subsection{Análise climatológica}

Analisando o gráfico 1, que correlaciona temperatura e umidade relativa do ar para o ponto $\mathrm{A}$, fica notável que a medida que se aumentam as áreas pavimentadas em substituição à vegetação original, tem-se uma piora nos índices de temperatura e umidade. A temperatura média e a umidade relativa do ponto $A$ foram 
de $29,08^{\circ} \mathrm{C} 60,3 \%$, respectivamente, em 2013/2014, enquanto em 2003/2004 apresentaram valores de $29,5^{\circ} \mathrm{C}$ e $63,3 \%$.

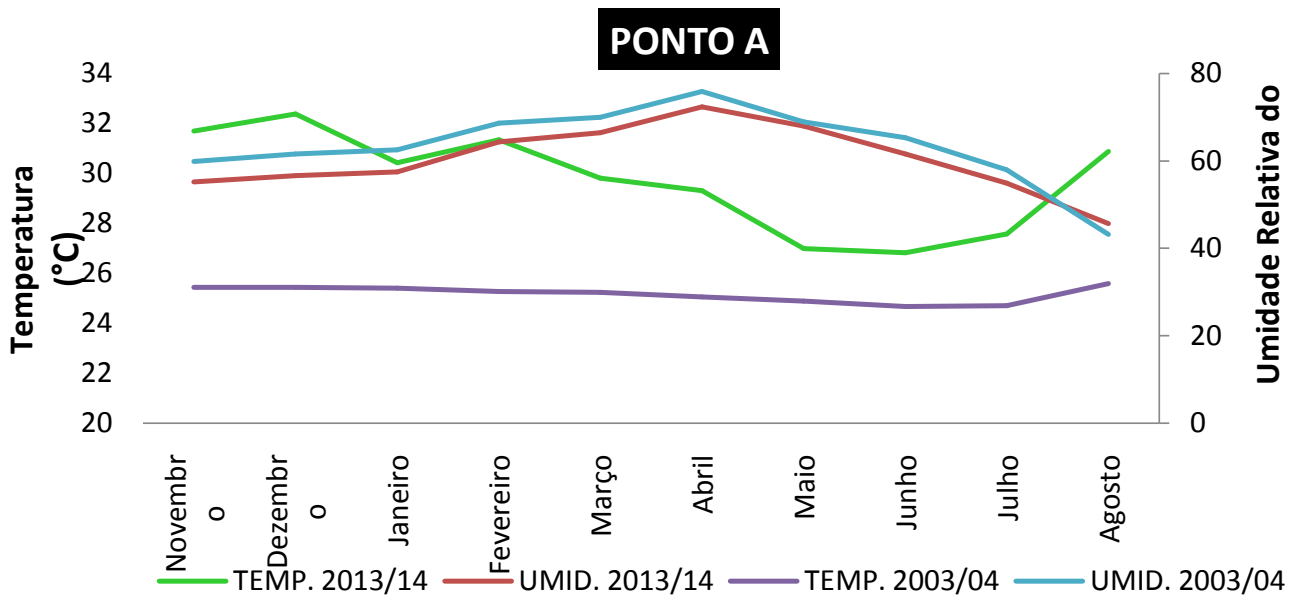

GRÁFICO 1 -Ponto A- relação temperatura x umidade 2003/04 e 2013/14 Fonte: Autoria própria

A temperatura média do ponto $\mathrm{B}$ sofreu um acréscimo de $29,1^{\circ} \mathrm{C}$ de $2003 / 2004$ para $30^{\circ} \mathrm{C}$, na década seguinte, enquanto a redução da umidade relativa média alcançou os 4,6\% (Gráfico 2).

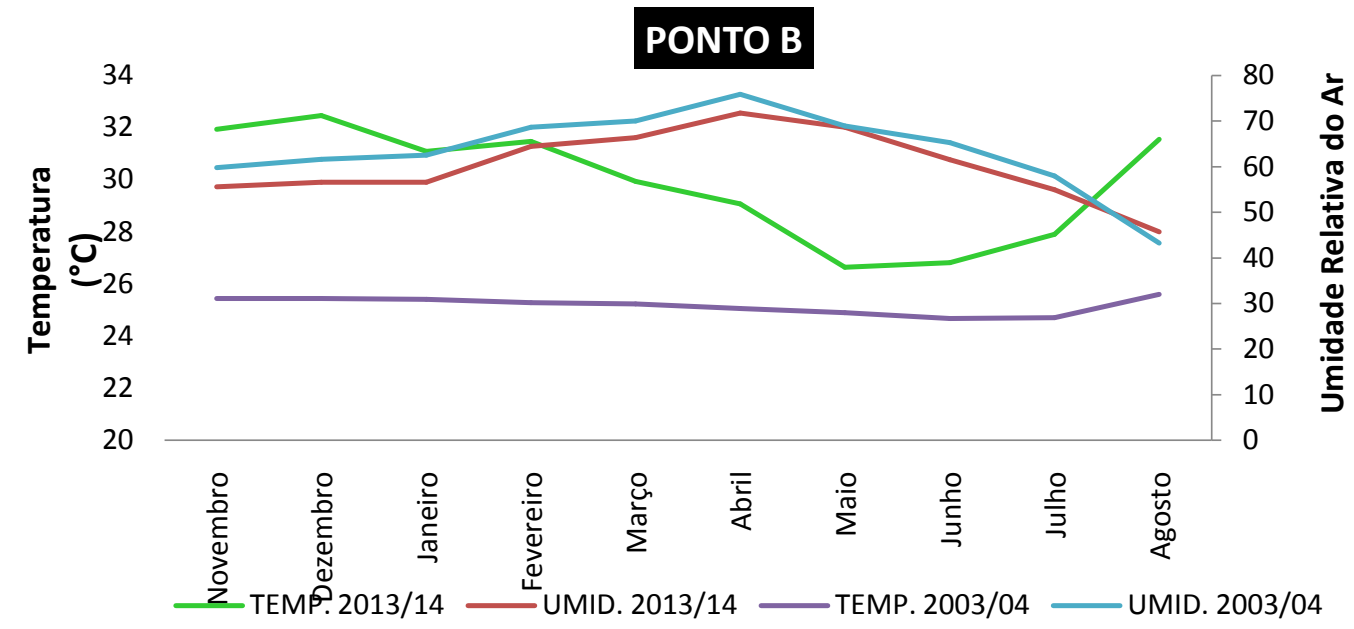

GRÁFICO 2 -Ponto B- relação temperatura x umidade 2003/04 e 2013/14

Fonte: Autoria própria

Com base no gráfico 3, analisa-se que o comportamento das variáveis pouco oscilou durante os meses analisados, sendo que as temperaturas médias se mantiveram constantemente mais altas em 2013/2014 em todo o período, porém a umidade relativa não se comportou de maneira uniforme. A temperatura média de Ciência e Sustentabilidade - CeS | Juazeiro do Norte v. 2, n. 1, p. 103-123, jan/jun 2016 
2003/2004 diminuiu em $0,3^{\circ} \mathrm{C}$ em relação à registrada nos dez anos posteriores, enquanto a umidade relativa se manteve praticamente a mesma. Tais valores evidenciam a importância da preservação da vegetação das áreas de entorno no conforto térmico urbano.

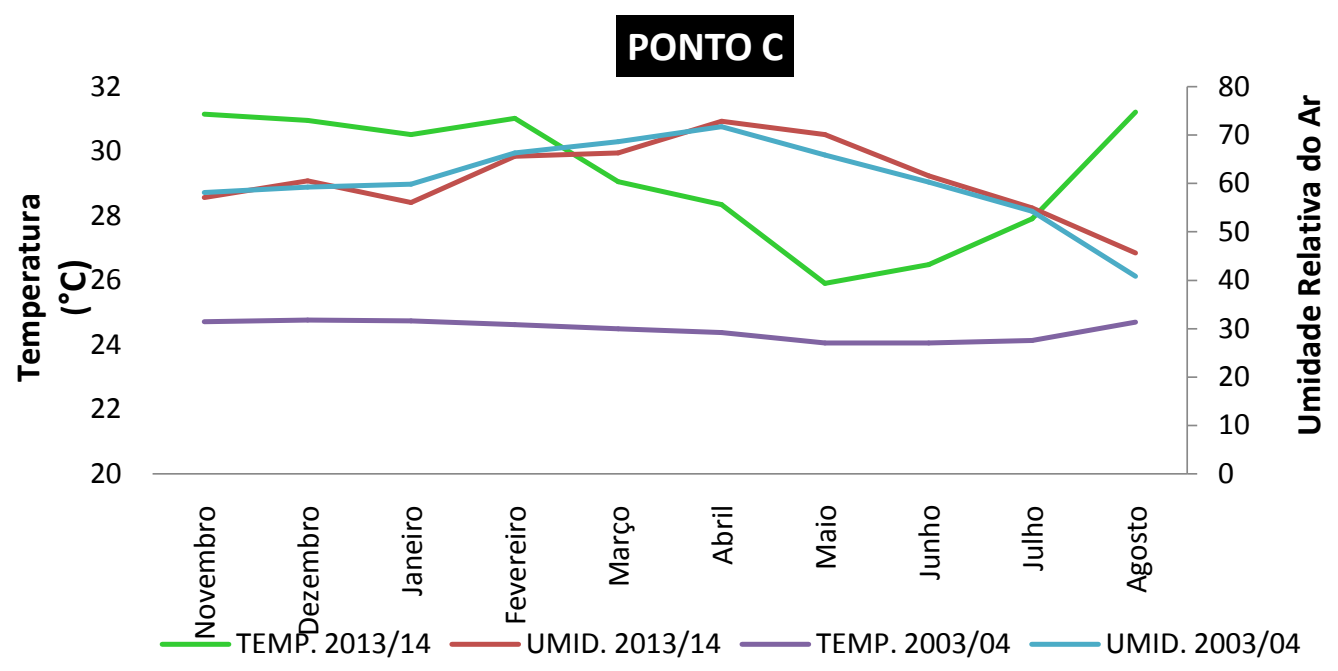

GRÁFICO 3 -Ponto C- relação temperatura x umidade 2003/04 e 2013/14

Fonte: Autoria própria

As maiores temperaturas médias e menores umidades relativas do ar se encontram nos pontos $A$ e $B$, pontos que se caracterizam pelo intenso fluxo de veículos, alta densidade de construções e crescimento urbano. $\mathrm{O}$ ponto $\mathrm{C}$, no entanto, se caracteriza como uma área pouco construída, próximo a áreas verdes e com uma tráfego de carros mais reduzido, o que reflete nos índices climáticos que melhoraram seus valores no período entre 2013/2014, comparando-se com os apresentados em 2003/2004.

\section{CONSIDERAÇÕES FINAIS}

A Lei Complementar $n^{0} 102$, analisada neste presente trabalho, em seus aspectos climatológicos possui diversos parâmetros, que se relacionam diretamente ao ambiente térmico urbano, seja pelo coeficiente de permeabilidade do solo o qual proporciona maior absorção de água e redução das temperaturas superficiais, pela regulação dos afastamentos mínimos entre edificações, promovendo a ventilação cruzada, seja pelo plantio regular de árvores a cada $5 \mathrm{~m}$ ao longo da cidade que 
aumenta as áreas de sombra e proteção dos pedestres contra a radiação solar direta, o potencial construtivo, coeficiente de aproveitamento e capacidade construtiva que limitam as áreas edificadas evitando grandes concentrações edificadas nos centros urbanos.

Nota-se pelos resultados, que tais parâmetros legais não são efetivamente concretizados pelo poder público, na prática diária de controle e adequação de novos ou antigos empreendimentos urbanos. Com isso geram-se em áreas de maior índice de crescimento um maior desequilíbrio em relação à ambiência térmica na cidade, o que seria minimizado caso os critérios propostos na Lei Complementar de $n^{\circ} 102$ de Cuiabá-MT, são de vital importância na garantia e manutenção de um ambiente térmico saudável aos moradores da capital mato-grossense.

O estudo de clima urbano, além da quantificação das alterações detectadas, torna fundamental uma análise geográfica do fenômeno, ou seja, estabelece relações entre os dados mensurados e os elementos componentes da cidade. (AMORIM, 2010). Alguns estudos como o de Gómez (2001) para Valência na Espanha, fornece algumas sugestões para o planejamento de áreas verdes ao indicar a quantidade de vegetação necessária para melhorar os índices de conforto, tendo em vista a condição climática mensurada.

Dessa forma, percebe-se que a adequação do planejamento urbano da cidade de Cuiabá à Lei $\mathrm{n}^{0} 102$ é uma tarefa conjunta entre governoe sociedade. Aliar a prática e controle de um plano diretor bem elaborado com um planejamento urbano e ambiental e leis complementares contundentes, tornam-se instrumentos extremamente necessários na busca de um ambiente térmico favorável e sadio estando comprometido com preceitos sustentáveis

Reforçando a importância de que as medidas legais de tentativa de adaptação sejam cumpridas em situações de crescimento não planejado e vulnerabilidade urbana, acrescenta-se o argumento de que desastres originados em eventos climáticos têm se ampliado, a despeito de certezas sobre o fenômeno de mudança climática, com danos em maior proporção nas áreas economicamente menos desenvolvidas do planeta. Disso decorre a importante noção de que os desastres são causados não pelo evento climático, mas por sua interação com as condições da ocupação, o que ressalta a importância da contribuição de planos diretores e leis complementares para a adaptação urbana. Decorre ainda, que 
medidas para adaptabilidade são necessárias e urgentes não apenas para evitar que condições climáticas futuras causem desastres, mas também para que os ambientes térmicos urbanos atuais sejam melhorados.

Os cidadãos podem contribuir através da regularização dos lotes respeitando os recuos e a porcentagem de área verde exigidos pela legislação. $O$ poder público deve cumprir a responsabilidade de orientar o uso e ocupação do solo, fiscalizando as obras e construções para que sejam atendidos os parâmetros exigidos pela lei e, assim, garantir a qualidade de vida dos cidadãos.

\title{
EVALUATION OF LAND USE AND OCUPATION IN THE NORTH REGION OF CUIABÁ-MT AND ITS RELATIONSHIP WITH THE SUPPLEMENTARY LAW N. 102
}

\begin{abstract}
The rapid and unplanned urbanization, combined with land use models, committed to environmental quality of large cities, resulting in significant changes in the urban climate and in relation to environmental comfort and physical and psychological health. The changes experienced by urbanization modify the urban climate by embossing, by variations in soil roughness and decrease of vegetation cover, and many other factors. This research deals with the relationship between the changes in microclimate variables and Complementary Law of use and occupation $n^{\circ} 102$, in the north of the city of Cuiabá. For this, we analyzed three points at AvenidaHistoriador Rubens de Mendonça, one of the main axes of expansion of the city, in a period of 10 years between 2003/2004 and 2013/2014. It compared temperature and relative humidity of the air with the changes undergone by the analyzed areas through legal parameters as the setbacks of the buildings, the presence of vegetation and permeability. The survey results allow us to affirm that climate conditions are directly linked to land use and especially with the lack of individual trees on site. In conclusion, it revealed the need to adapt the territorial space to the legal guidelines of urban planning.
\end{abstract}

Keywords: Thermal comfort. Law. Urban planning.

\section{REFERÊNCIAS}

AMORIM, M..Climatologia e Gestão do Espaço Urbano (climatologyandurbanspace management).Revista Mercator, América do Norte, 913012011.

ASSIS, E. S. Impactos da forma urbana na mudança climática: método para previsão do comportamento térmico e melhoria de desempenho do ambiente urbano. Tese (Doutorado) - Faculdade de Arquitetura e Urbanismo da Universidade de São Paulo. São Paulo, 2000.

BERNATZKY, A. The contribution of trees and green spaces to a town climate. In.: Energy and Buildings, Vol. 5, 10p., 1982. p. 1-10. 
BUENO, C. L. A influência da vegetação no conforto térmico urbano e no Ambiente construído. Tese (Doutorado em Saneamento e Ambiente) - Faculdade de Engenharia Civil, Universidade Estadual de Campinas. 186 p., Campinas, 2003.

CHANGNON, S. A. Inadverted weather modification in urban areas: lessons for global climate change. Bulletin American MeteorologicalSociety, n. 73, p. 619627, 1992

CARVALHO, H. J. M. Metodologia para a análise das interações entre a forma urbana e o clima: aplicação a uma cidade brasileira de clima litorâneo com baixa latitude. Tese (Doutorado em Urbanismo) - Programa de Pós-Graduação em Urbanismo, Faculdade de Arquitetura e Urbanismo, Universidade Federal do Rio de Janeiro, Rio de Janeiro, 2006.

CUIABÁ. Prefeitura. Instituto de Planejamento e Desenvolvimento Urbano - IPDU. Diretoria Estadual de Pesquisa e Informação - DPI. Perfil pelo governo socioeconômico de Cuiabá, volume IV. Organização Adriana Bussiki Santos; coordenação Jandira Maria Pedrollo. Cuiabá: 2010.

DA SILVA, Isadora Mendes; GONZALEZ, Luciana Ruggiero; DA SILVA FILHO, Demóstenes Ferreira. Recursos naturais de conforto térmico: um enfoque urbano. REVSBAU, Piracicaba - SP, v.6, n.4, p. 35-50, 2011.

EMMANUEL, R. An Urban Approach to Climate Sensitive Design:Strategies for the Tropics. Spon Press: London, 2005.

FIALHO, E.S. Ilhas de calor: reflexões acerca de um conceito. ACTA Geográfica, Boa Vista, Ed. Esp. Climatologia Geográfica, 2012. pp.61-76

GOMES, P.S. LAMBERTS, R. O estudo do clima urbano e a legislação urbanística: considerações a partir do caso Montes Claros, MG. Ambiente Construído, Porto Alegre, v. 9, n. 1, p. 73-91, jan./mar. 2009.

GÓMEZ, F; TAMARIT, N.; JABALOYES, J. Green zones, bioclimatic studies and human confort in the future development of urban planning. Lanscape and Urban Planning, n. 55, 2001.

KATZCHNER, L. Urban climate studies as tools for urban planning and architecture, in: EncontroNacional de Conforto no AmbienteConstruído, 4o, Salvador, 1997.

Anais... Salvador: FAU/UFBA, ANTAC, p. 49-58.

KOTKIN, Joel. A Cidade: uma história global. Rio de Janeiro: Objetiva, 2012

KRÜGER, E. L.; DRACH, P. L. C.; EMMANUEL, R.; CORBELLA, O. D. Estudo de conforto em espaços abertos em região de clima temperado: o caso de Glasgow, Reino Unido. Ambiente Construído, Porto Alegre, v. 12, n. 1, p. 7-25, jan./mar. 2012. 
LAMBERTS, R. et al., Building Bioclimatology in Brazil. In: The 14 th International Conference on Passive and Low Energy Architecture. PLEA 97, Kushiro, Japan.

Proceedings... 1997. p. 203-208.

LEÃO,E.F.B.T.Carta Bioclimática de Cuiabá - Mato grosso. Cuiabá. 2007 147p.Dissertação (Mestrado em Física e Meio Ambiente), Departamento de Física, Instituto de Ciências Exatas e da Terra, Universidade Federal de Mato Grosso.

LIMA, B. R. O.; NERY, J. T. Clima Urbano no município de Ourinhos. Ourinhos: FAPESP - Relatório Parcial de Iniciação Cientifica, jan. 2008.

LIMA, Lorena Cavalcante; ZANELLA, Maria Elisa. A Climatologia aplicada ao planejamento urbano e ambiental de Aquiraz/CE-BR. Revista Geográfica de América Central, v. 2, n. 47E, 2011.

MACIEL, C. R. Análise da relação entre características do ambiente urbano e o comportamento de variáveis microclimáticas: estudo de caso em Cuiabá-MT. Tese (Doutorado). Universidade Federal de Mato Grosso. 2011. 127p.

MAITELLI, G. T. Uma abordagem Tridimensional do clima urbano em área Tropical Continental: o exemplo de Cuiabá/MT. Tese (Doutorado em Climatologia) - USP, São Paulo, 1994.

MONTEIRO, C. A. de F. Teoria e Clima Urbano. São Pulo: IGEOG/USP, 1976. 181p. (SérieTeses e Monografias, 25)

OLGYAY, V. Design with Climate Bioclimatic Approach to Architectural Regionalism.4th ed. Princeton, New Jersey, U.S.A. Princeton University Press, 1963.

ROMERO, M. B. Arquitetura bioclimática do espaço público. Brasília: UnB, 2001.

SAMPAIO, Mariza de Mello Arruda. A Lei de Uso e Ocupação do Solo de CuiabáMT e suas Consequências Ambientais. Tese (Doutorado em Urbanismo), Programa de Pós-Graduação em Urbanismo (PROURB), Faculdade de Arquitetura e Urbanismo (FAU), Universidade Federal do Rio de Janeiro (UFRJ), Rio de Janeiro 2015. 